on the problem of alcoholism in the USSR and on media reports of Soviet airforce personnel consuming aircraft de-icing fluid (N.B. not engine fluid). However, I did not and should not have intended to put my points in such terms as were published. I sincerely hope they will not have caused offence.

The Bethlem Royal Hospital ROBIN JACOBY

Monks Orchard Road

Beckenham

Kent BR3 3BX

\section{Distress caused by miscarriage}

SIR: Milner (Journal, July 1989, 155, 127) raises the issue of the amount of distress caused by miscarriage. Research shortly to be published in this Journal (Friedman \& Gath, 1989) indicates high levels of distress in a group of women one month after miscarriage. In a series of 67 women, $48 \%$ PSE cases and two cases of self-harm not known to the medical profession were found. Another paper (Friedman, 1989) discusses the dissatisfaction of patients with their management and the problems of caring for this group of patients.

I agree with Dr Milner on the need for doctors and nurses to be more aware of this distressing condition, and that quite simple intervention may be effective in alleviating the considerable emotional turmoil caused.

Department of Psychiatry

University Hospital

Nottingham NG7 2UH

\section{References}

Friedman, T. \& GATH, D. (1989) The psychiatric effects of spontaneous abortions. BritishJournal of Psychiatry (in press)

Frirdman, T. (1989) General practitioners' management of miscarriage. Journal of the Royal College of General Practitioners (in press).

\section{CPK levels and neuroleptic malignant syndrome}

SIR: I was interested to read Maharajh's letter (Journal, June 1989, 154, 885-886), as our District Biochemist, Mr G. Trevis, and I have recently started looking at the interpretation of CPK levels (including isoforms of MM isoenzymes) in the face of many variables. For example, elevated levels have been found in acute cerebral disorders, head injury, alcohol excess, muscle diseases, after oral neuroleptics, and in renal, cardiac, or thyroid dysfunction.

Some years ago there was considerable interest in elevated levels of CPK in patients with acute psy- chosis, and now more recently in raised CPK in neuroleptic malignant syndrome (NMS). I would suggest that a diagnosis of NMS should depend far more on clinical examination than finding a raised $C P K$. It has been suggested that the raised levels in acute psychotic patients may well be due to increased motor activity (Goode et al, 1979) or even intramuscular injections, but a study by Kumar (1984) looking at levels of CPK in schizophrenics and their first-degree relatives compared with normal controls found not only significantly raised CPK levels in the patient population but also in the first-degree relatives compared with normal subjects. The phenomenon of malignant hyperthermia has much in common with NMS, and again has been associated with increased CPK levels, and at one time it was thought that a raised level may predict a susceptibility to malignant hyperthermia, although this was subsequently refuted (Paasuke \& Brownell, 1986).

Finally, I note that Dr Maharajh questions what the levels of CPK may be in black psychotic patients without NMS. Earlier work (Meltzer \& Holy, 1974) has suggested that there are sex-race differences in serum CPK activity, levels being highest among black males and lowest among white females, and more recently a study by Gledhill et al (1988) confirmed that black males had higher CPK levels than white males.

\section{Barnsley Hall Hospital \\ Stourbridge Road \\ Bromsgrove B61 OEX}

SHeElah James

\section{References}

Gledhill, R. F., Van Der Merwe, C. A., Greyling, M. el al (1988) Race-gender differences in serum creatine kinase activity: a study among South Africans. Journal of Neurology;, Neurosurgery \& Psychiatry, 51, 301-304

Goode, D. J., Meltzer, H. Y., Morrett, R. el al (1979) The relationship between wrist monitored motor activity and serum CPK activity in psychiatric in-patients. British Journal of Psychiatry, 135, 62-66.

Kumar, A., Upadhyaya, G. L. \& Trivedi, J. K. (1984) Serum CPK levels in schizophrenics and their first degree relatives. Indian Journal of Physiology and Pharmacology, 28, 128-132.

MELTZER, H. Y. \& Holy, P. A. (1974) Black-white differences in serum creatine phosphokinase (CPK) activity. Clinica Chimica Acta, 54, 215-224.

PaAsuke, R. T. \& Brownell, A. K. (1986) Serum creatine kinase level as a screening test for susceptibility to malignant hyperthermia. Journal of the American Medical Association. 255, 769-771.

\section{Paradoxical intervention}

SiR: Macdonald's letter (Journal, June 1989, 154, 883) has prompted me to read the case report of use of paradoxical intervention in a ritualist woman 